\title{
8-Hydroxy-2'-deoxyguanosine expression predicts hepatocellular carcinoma outcome
}

\author{
SHENGMIAN LI ${ }^{1}$, XIAOLING WANG ${ }^{2}$, YIJUAN WU ${ }^{1}$, HUIJING ZHANG ${ }^{1}$, \\ LAN ZHANG $^{1}$, CUIJU WANG ${ }^{3}$, RUIXING ZHANG ${ }^{1}$ and ZHANJUN GUO ${ }^{1,4}$ \\ Departments of ${ }^{1}$ Gastroenterology and Hepatology, ${ }^{2}$ Pathology, and ${ }^{3}$ Gynecology Ultrasound, \\ The Fourth Hospital of Hebei Medical University; ${ }^{4}$ Hebei Key Lab of Laboratory Animal Science, \\ Hebei Medical University, Shijiazhuang, Hebei 050011, P.R. China
}

Received June 6, 2011; Accepted November 2, 2011

DOI: $10.3892 / 01.2011 .477$

\begin{abstract}
Hepatocellular carcinoma (HCC) is characterized by increased oxidative stress and the production of 8-hydroxy-2'-deoxyguanosine (8-OHdG), which is one of the main mutagenic modifications of DNA by oxidative stress. We analyzed the association of $8-\mathrm{OHdG}$ with post-operative survival and revealed that low levels of 8-OHdG are associated with significantly shorter survival time. Moreover, levels of 8-OHdG were associated with HCC characteristics, including tumor size, tumor quantity, clinical staging, Child classification, portal vein thrombosis and ascites. These results suggest that oxidative damage is a useful prognostic marker in $\mathrm{HCC}$ when other clinical characteristics are present with 8-OHdG.
\end{abstract}

\section{Introduction}

Many reactive oxygen species (ROS), formed as by-products of energy production in aerobic animals, cause damage to macromolecules such as DNA, proteins and lipids, and are thus involved in a variety of biological processes, including aging, cancer and degenerative diseases (1). The hydroxyl radical is responsible for a number of base modifications, including thymine glycol and 8-hydroguanine (2). Oxidative damage to 2'-deoxyguanosine produces 8-hydroxy-2'-deoxyguanosine (8-OHdG), which induces G-C to T-A transversion in daughter DNA strands. In previous studies, $8-\mathrm{OHdG}$ was shown to be a useful marker for assessing oxidative DNA damage $(3,4)$, and levels of $8-\mathrm{OHdG}$ in animal organ DNA have been used to assess the risk of carcinogenesis (5).

Hepatocellular carcinoma (HCC) is the fifth most frequent type of human cancer worldwide and the third highest cause of cancer-related mortality (6). More than $95 \%$ of HCC cases

Correspondence to: Dr Zhanjun Guo, Department of Gastroenterology and Hepatology, The Fourth Hospital of Hebei Medical University, 12 Jiankang Road, Shijiazhuang 050011, P.R. China

E-mail: zjguo5886@yahoo.com.cn

Key words: 8-OHdG, hepatocellular carcinoma, outcome, survival arise with a background of persistent inflammatory disease. The disease etiologies are diverse, although the hepatitis B virus (HBV) and hepatitis $\mathrm{C}$ virus (HCV) are implicated in the majority of cases (7).

Increased oxidative stress is associated with hepatitis viral infections and HCC progression $(8,9)$. Free radical production is increased at the site of inflammation, resulting in lipid peroxidation and oxidative DNA damage, which are risk factors for HCC $(10,11) .8-\mathrm{OHdG}$ is well known as a high risk factor for HCC in chronic HCV infection $(9,12)$. The prognosis for post-operative HCC patients remains poor due to high recurrence rates in spite of improved clinical detection methods for earlier diagnosis. Various factors, including tumor size, quantity of tumors, cell differentiation, venous invasion, advanced pTNM stage and degree of inflammation, have proven to be predictors for recurrence and prognosis for HCC patients. However, only a limited number of studies have focused on the relationship between oxidative markers and HCC prognosis (13-16). Since 8-OHdG has been used as a biomarker with prognostic significance for several types of cancer (17-19), we assessed the predictive power of 8-OHdG on HBV-HCC prognosis and examined the correlation between 8-OHdG and clinical characteristics of HBV-HCC. The post-operative HCC patients enrolled in this study were followed up with regular visits in our hospital. Tumor recurrence was diagnosed by laboratory tests combined with contrast-enhanced computed tomography (CT) or contrastenhanced magnetic resonance imaging (MRI), and the overall survival rate was recorded.

\section{Materials and methods}

Tissue collection. We obtained histologically confirmed hepatic cancerous tissues from $110 \mathrm{HCC}$ patients, including 95 patients with HBV associated with HCC (HBV-HCC) and 15 patients with $\mathrm{HCV}$ associated with $\mathrm{HCC}$ (HCV-HCC), who received an HCC resection operation between January 2002 and June 2004 at the Hepatobiliary Surgery Department in the Fourth Hospital of Hebei Medical University, China, according to the guidelines of the human tissue research committee at the hospital. Tissues were fixed in formalin (10\%) immediately after resection, dehydrated in absolute ethanol and embedded in 
paraffin. Serial sections $(5 \mu \mathrm{m})$ were prepared for immunohistochemical analysis. All patients received and signed consent forms and all procedures were supervised and approved by the hospital's Human Tissue Research Committee.

Measurement of 8-OHdG in hepatocarcinoma cancer tissues. The $8-\mathrm{OHdG}$ levels were measured by hepatic immunohistochemical staining. Briefly, tissue sections were incubated for 2 days at $4^{\circ} \mathrm{C}$ with anti-8-OHdG antibody (dilution 1:100; Abcam, Cambridge, UK) and then reacted with biotinylated secondary anti-mouse IgG antibody for $1 \mathrm{~h}$ at room temperature. Streptavidin was added and the color was developed with 3,3'-diaminobenzidine (DAB).

The level of 8-OHdG was measured as described (13). Two pathologists counted the number of 8-OhdG-stained hepatocytes in 10 random fields (magnification, $x 400$ ). We calculated the percentage of positively stained cells, which was termed the 8-OHdG label index (LI), in each field and graded them as follows: low, LI <50\%; high, LI >50\% (Fig. 1).

Statistical analysis. The survival data were analyzed by the Kaplan-Meier method, differences were determined by the log-rank test and the prognostic significance of clinical characteristics was assessed by the multivariate Cox proportional hazard model. Differences in clinical characteristics between the high and low LI groups were compared with the $\chi^{2}$ test. $\mathrm{P} \leq 0.05$ was considered to be statistically significant and all calculations were performed using SPSS 11.5 software (SPSS Inc., Chicago, IL, USA).

\section{Results}

Clinical characteristics of $H B V-H C C$ patients. A total of 110 patients were enrolled in this study and a review was conducted every 3 months for 3 years. Seven patients were lost during follow-up; one $\mathrm{HBV}-\mathrm{HCC}$ patient in the first year, one HCV-HCC and three HBV-HCC patients in the second year and one HCV-HCC and one HBV-HCC patient in the third year. The remaining 103 patients (90 HBV-HCC and 13 HCV-HCC) were assessed. Adjuvant chemotherapy or radiation therapy were not administered following HCC resection. The data collected during the 3-year follow-up were analyzed for clinical characteristics as described in Materials and methods. No difference was observed for gender, age, tumor size, tumor quantity, Child classification, clinical stage, portal vein thrombosis or ascites between HBV-HCC and HCV-HCC patients, so we combined them for further analysis. Age was not a significant predictor for post-operative survival time, but gender, tumor size, tumor quantity, tumor stage, Child classification, portal vein thrombosis and ascites were positively correlated with survival time (Table I). The 3-year survival rate was $14.8 \%$ for the 18 female patients and $36.7 \%$ for the 85 male patients. Patients with tumor diameter $\geq 5 \mathrm{~cm}$ had a significantly shorter survival time than those with tumor diameter $<5 \mathrm{~cm}$. As expected, patients at different stages of the disease had significantly different 3-year survival rates as determined by the log-rank test: stage I-II, $44.1 \%$ and stage III-IV, $3.9 \%$. Patients with portal vein thrombosis had a significantly shorter survival time than patients without venous invasion. Child classification and ascites were associated with HCC survival.
Table I. Univariate analysis of clinical characteristics associated with post-operational survival in HCC patients.

\begin{tabular}{|c|c|c|}
\hline Characteristics & $\begin{array}{l}\text { No. of } \\
\text { cases }\end{array}$ & $\begin{array}{c}\text { 5-yr survival } \\
\text { rate }(\%)\end{array}$ \\
\hline
\end{tabular}

\begin{tabular}{|c|c|c|c|}
\hline Gender & & & 0.023 \\
\hline Male & 85 & & \\
\hline Female & 18 & 14.8 & \\
\hline Age (years) & & & 0.964 \\
\hline$\leq 55$ & 43 & 35.4 & \\
\hline$>55$ & 60 & 31.7 & \\
\hline Quantity of tumors & & & 0.001 \\
\hline Single & 68 & 39.2 & \\
\hline Multiple & 35 & 19.4 & \\
\hline Diameter of tumor $(\mathrm{cm})$ & & & 0.023 \\
\hline$<5$ & 33 & 47 & \\
\hline$\geq 5$ & 70 & 25.3 & \\
\hline TNM classification & & & 0.000 \\
\hline I-II & 73 & 44.1 & \\
\hline III-IV & 30 & 3.9 & \\
\hline Child classification & & & 0.000 \\
\hline A & 85 & 37.7 & \\
\hline $\mathrm{B}+\mathrm{C}^{\mathrm{a}}$ & 18 & 7.2 & \\
\hline Portal vein thrombosis & & & 0.000 \\
\hline Yes & 46 & 9.7 & \\
\hline No & 57 & 51.1 & \\
\hline Ascites & & & 0.040 \\
\hline Yes & 44 & 28 & \\
\hline No & 59 & 33.4 & \\
\hline
\end{tabular}

${ }^{\mathrm{a} A s}$ there were only 4 Child $\mathrm{C}$ patients, $\mathrm{B}$ and $\mathrm{C}$ patients were combined to form one group.

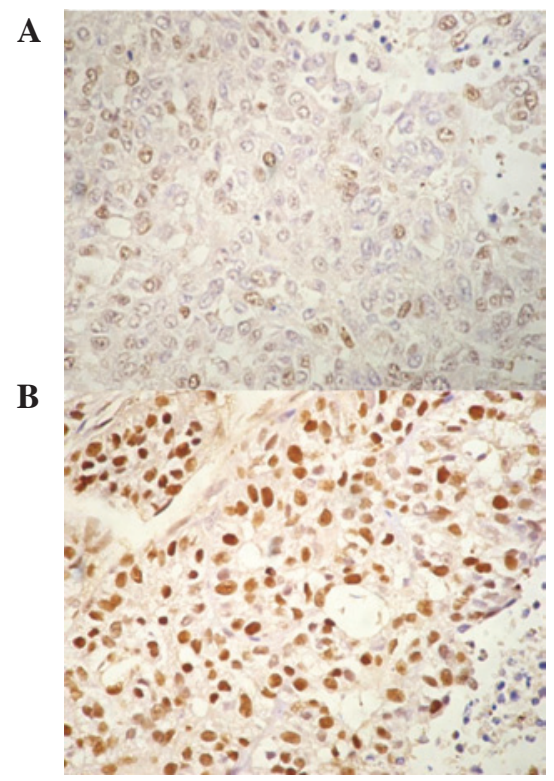

Figure 1. 8-OHdG immunostaining in HCC tissues with (A) low expression and (B) high expression. Cells with a brown-stained nucleus are regarded as positive. Original magnification, $\mathrm{x} 400$. 
Table II. Multivariate analysis of prognostic factors associated with post-operational survival in HCC patients with the Cox proportional hazard model.

\begin{tabular}{lccc}
\hline Factors & Relative risk & $95 \% \mathrm{CI}$ & P-value \\
\hline Gender & 1.153 & $0.589-2.258$ & 0.678 \\
Tumor quantity & 2.057 & $1.152-3.674$ & 0.015 \\
Size of the tumor & 0.779 & $0.427-1.423$ & 0.417 \\
TNM classification & 0.369 & $0.158-0.862$ & 0.021 \\
Child classification & 1.735 & $1.026-2.932$ & 0.040 \\
Portal vein & 2.934 & $1.376-6.256$ & 0.005 \\
thrombosis & & & \\
Ascites & 1.420 & $0.835-2.415$ & 0.195 \\
8-OHdG & 0.152 & $0.051-0.455$ & 0.001 \\
\hline
\end{tabular}

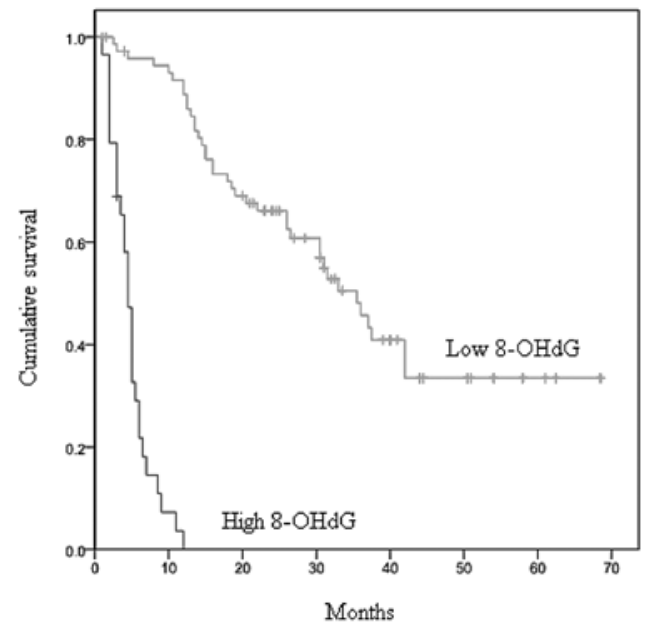

Figure 2. Significant survival difference between HCC patients in low and high $8-\mathrm{OHdG}$ groups $(\mathrm{p}=0.000)$.

The data demonstrated that gender, tumor size, tumor quantity, tumor stage, Child classification, venous invasion and ascites are good predictors of HCC outcome.

8-OHdG level predicts prognosis of HCC patients. The immunoreactivity of $8-\mathrm{OHdG}$ observed in HBV-HCC tissues occurred mostly in the nuclei (Fig. 1). We graded the LI (the percentage of $\mathrm{HCC}$ cells containing $8-\mathrm{OHdG}$ ) as low or high for the 3-year analysis and the cumulative survival rate was plotted as a Kaplan-Meier curve (Fig. 1). As shown in Fig. 2, the log-rank test revealed a markedly significant difference $(p=0.000)$ between the low and high LI groups demonstrating the usefulness of the oxidative DNA damage marker 8-OHdG in predicting the prognosis of HBV-HCC.

Multivariate analysis of prognosis factors for $\mathrm{HBV}$-HCC. We used a multivariate analysis, including the predictors mentioned above, with the Cox proportional hazard method to evaluate the effect of this unusual oxidative DNA marker on the predictive power of traditional clinical parameters. The analysis revealed that the 8-OHdG level, tumor quantity, clinical stage and portal vein thrombosis were independent
Table III. Association of $8-\mathrm{OHdG}$ with $\mathrm{HCC}$ clinical characteristics.

\begin{tabular}{|c|c|c|c|}
\hline \multirow[t]{2}{*}{ Characteristics } & \multicolumn{2}{|c|}{ 8-OHdG } & \multirow[t]{2}{*}{ P-value } \\
\hline & Low & High & \\
\hline Gender & & & 0.091 \\
\hline Male & 64 & 21 & \\
\hline Female & 10 & 8 & \\
\hline Age (years) & & & 0.692 \\
\hline$\leq 55$ & 30 & 13 & \\
\hline$>55$ & 44 & 16 & \\
\hline Numbers of the tumor & & & 0.001 \\
\hline Single & 56 & 12 & \\
\hline Multiple & 18 & 17 & \\
\hline Diameter of the tumor & & & 0.044 \\
\hline$<5$ & 46 & 24 & \\
\hline$\geq 5$ & 28 & 5 & \\
\hline TNM classification & & & 0.000 \\
\hline I-II & 67 & 6 & \\
\hline III-IV & 7 & 23 & \\
\hline Child classification & & & 0.000 \\
\hline A & 70 & 15 & \\
\hline $\mathrm{B}+\mathrm{C}$ & 4 & 14 & \\
\hline Portal vein thrombosis & & & 0.000 \\
\hline Yes & 19 & 27 & \\
\hline No & 55 & 2 & \\
\hline Ascites & & & 0.003 \\
\hline Yes & 25 & 19 & \\
\hline No & 49 & 10 & \\
\hline
\end{tabular}

risk factors for the post-operative survival rate of $\mathrm{HBV}-\mathrm{HCC}$ patients (Table II). Among the predictors, 8-OHdG had the strongest link to the HBV-HCC survival rate, with a hazard ratio of 0.152 (95\% CI, 0.051-0.455). Univariate and multivariate analyses suggested that the $8-\mathrm{OHdG}$ level in HCC tissue DNA is one of the best predictors of the post-operative survival rate of HCC patients.

Correlation between 8-OHdG and other predictors of $H B V-H C C$. The correlation of clinical characteristics and 8-OHdG levels was evaluated in HCC patients using the $\chi^{2}$ test and the results are shown in Table III. Gender and age were not correlated with 8-OHdG levels, whereas tumor size, tumor quantity, clinical stage, Child classification, portal vein thrombosis and ascites were significantly correlated with $8-\mathrm{OHdG}$ expression. The data suggest that $8-\mathrm{OHdG}$ is capable of modifying tumor development in combination with other predictors.

\section{Discussion}

We used immunohistochemical methods with a monoclonal antibody against $8-\mathrm{OHdG}$ with paraffin-embedded HCC sections for the assessment of oxidatively damaged DNA in 
HBV-HCC patients. The 8-OHdG generated as a result of oxidative DNA damage is capable of inducing mutations in genes and is closely involved in hepatocarcinogenesis $(5,9,12,20)$. We demonstrated that $8-\mathrm{OHdG}$ expression levels in cancer tissues were associated significantly with the 3 -year post-operative survival rate in $\mathrm{HBV}-\mathrm{HCC}$ patients. The $8-\mathrm{OHdG}$ levels were a risk factor for hepatocarcinogenesis and a good marker for predicting the outcome of post-operative HBV-HCC patients. Earlier studies suggested that oxidative DNA damage was associated with cancer progression, including cell proliferation, apoptosis, genetic instability and chemoresistant phenotypes (21-24), whereas the functional significance of persistent oxidative stress in $\mathrm{HCC}$ tissue remains unknown.

Consistent with the results of earlier studies, we found that tumor quantity, venous invasion, advanced pTNM staging and Child classification were independent predictors for HCC. We found these predictors to be correlated with 8-OHdG expression levels, suggesting that there is an intrinsic interaction between oxidative stress and the characteristics associated with HCC outcome. Miyake et al revealed an association between 8-OHdG expression and tumor size, clinical stage and venous invasion in the progression of renal cell carcinoma (17). Whether oxidative damage is the cause of these clinical characteristics, thus affecting tumor progression indirectly, or whether it modifies the tumor progression directly in cooperation with these characteristics requires further analysis.

The degree of inflammation is associated with hepatocarcinogenesis and outcome in HCC patients $(13,25)$. Hepatic oxidative stress is associated with hepatic inflammation in viral hepatitis patients $(9,26)$. It is unclear whether oxidative stress is the cause or the consequence of liver injury, but it has been demonstrated that the oxidative stress directly activates Kuffer cells, causing the release of inflammatory and profibrogenic cytokines, including tumor necrosis factor- $\alpha$ and transforming growth factor- $\beta$ (27). Oxidative stress has been shown to have a significant association with hepatic fibrosis (28). Further clinical trials are required to evaluate the effect of anti-oxidative therapy on the survival of post-operative HBV-HCC patients.

In conclusion, we report that $8-\mathrm{OHdG}$ is a novel prognostic factor in HCC. The strong association between 8-OHdG expression and poor patient survival together with the correlation between clinical staging, Child classification, tumor size and venous invasion, suggests a significant role for oxidative stress in HCC carcinogenesis and tumor behavior. Further studies are required to clarify whether extensive oxidative stress in highly malignant tumors is a prerequisite for carcinoma progression or secondary changes during carcinogenesis.

\section{Acknowledgements}

This study was supported by the National Natural Science Foundation of China (no. 30801384). The study was supported in part by the Natural Science Foundation of Hebei Province (no. C2008000958).

\section{References}

1. Ames BN, Shigenaga MK and Hagen TM: Oxidants, antioxidants, and the degenerative diseases of aging. Proc Natl Acad Sci USA 90: 7915-7922, 1993.
2. Shigenaga M, Gimeno CJ and Ames BN: Urinary 8-hydroxy2'-deoxyguanosine as a biomarker of in vivo oxidative DNA damage. Proc Natl Acad Sci USA 86: 9697-9701, 1989.

3. Halliwell B: Why and how should we measure oxidative damage in nutritional studies? How far could you come? Am J Clin Nutr 72: 1082-1087, 2000.

4. Nakae D, Kobayashi Y, Akai H, Andoh N, Satoh H, Ohashi K, Tsutsumi M and Konishi Y: Involvement of 8-hydroxyguanine formation in the initiation of rat liver carcinogenesis by low dose levels of N-nitrosodiethylamine. Cancer Res 57: 1281-1287, 1997.

5. Kasai H: Analysis of a form of oxidative DNA damage 8-hydroxy-2'-deoxyguanosine, as a marker of cellular oxidative stress during carcinogenesis. Mutat Res 387: 147-163, 1997.

6. Block TM, Mehta AS, Fimmel CJ and Jordan R: Molecular viral oncology of hepetocellular carcinoma. Oncogene 22: 5093-5107, 2003.

7. Waris $\mathrm{G}$ and Siddiqui A: Regulatory mechanisms of viral hepatitis B and C. J Biosci 28: 311-321, 2003.

8. Schwarz KB: Oxidative stress during viral infection: a review. Free Radical Biol Med 21: 641-649, 1996.

9. Tanaka H,Fujita N, Sugimoto R, Urawa N, Horiike S, Kobayashi Y, Iwasa M, Ma N, Kawanishi S, Watanabe S, Kaito M and Takei Y: Hepatic oxidative DNA damage is associated with increased risk for hepatocellular carcinoma in chronic hepatitis $\mathrm{C}$. Br J Cancer 98: 580-586, 2008.

10. Hussain SP, Hofseth LJ and Harris CC: Radical causes of cancer. Nat Rev Cancer 3: 276-285, 2003.

11. De Maria N, Colantoni A, Fagiuoli S, Liu GJ, Rogers BK, Farinati F, Van Thiel DH and Floyd RA: Association between reactive oxygen species and disease activity in chronic hepatitis C. Free Radic Biol Med 21: 191-295, 1996.

12. Chuma M, Hige S, Nakanishi M, Ogawa K, Natsuizaka M, Yamamoto Y and Asaka M: 8-hydroxy-2'-deoxy-guanosine is a risk factor for development of hepatocellular carcinoma in patients with chronic hepatitis $\mathrm{C}$ virus infection. J Gastroenterol Hepatol 23: 1431-1436, 2008.

13. Maki A, Kono H, Gupta M, Asakawa M, Suzuki T, Matsuda M Fujii $\mathrm{H}$ and Rusyn I: Predictive power of biomarkers of oxidative stress and inflammation in patients with hepatitis $\mathrm{C}$ virusassociated hepatocellular carcinoma. Anals Surg Oncol 14: 1182-1190, 2007.

14. Okada S, Shimada K, Yamamoto J, Takayama T, Kosuge T, Yamasaki S, Sakamoto M and Hirohashi S: Predictive factors for postoperative recurrence of hepatocellular carcinoma. Gastroenterology 106: 1618-1624, 1994.

15. Minagawa M,Makuuchi M,Takayama T and Kokudo N: Selection criteria for repeat hepatectomy in patients with recurrent hepatocellular carcinoma. Ann Surg 238: 703-710, 2003.

16. Tung-Ping Poon R, Fan ST and Wong J: Risk factors, prevention, and management of postoperative recurrence after resection of hepatocellular carcinoma. Ann Surg 232: 10-24, 2000.

17. Miyake H, Hara I, Kamidono S and Eto H: Prognostic significance of oxidative DNA damage evaluated by 8-hydroxy2 -deoxyguanosine in patients undergoing radical nephrectomy for renal cell carcinoma. Urology 64: 1057-1061, 2004.

18. Murtas D, Piras F, Minerba L, Uglade J, Floris C, Maxia C, Demurtas P, Perra MT and Sirigu P: Nuclear 8-hydroxy-2'-deoxyguanosine as survival biomarker in patients with cutaneous melanoma. Oncol Rep 23: 329-335, 2010.

19. Karihtala P, Soini Y, Vaskivuo L, Bloigu R and Puistola U: DNA adduct 8-Hydroxyguanosine, a novel putative marker of prognostic significance in ovarian carcinoma. Int J Gynecol Cancer 19: 1047-1051, 2009.

20. Floyd RA: The role of 8-hydroxyguanine in carcinogenesis. Carcinogenesis 11: 1447-1450, 1990.

21. Tanaka T, Kondo S, Iwasa Y, Hiai H and Toyokuni S: Expression of stress response and cell proliferation genes in renal cell carcinoma induced by oxidative stress. Am J Pathol 156: 2149-2157, 2000.

22. Inoue S and Kawanishi S: Oxidative DNA damage induced by simultaneous generation of nitric oxide and superoxide. FEBS Lett 371: 86-88, 1995.

23. Erhola M, Toyokuni S, Okada K, Tanaka H, Hiai H, Ochi K, Uchida T, Osawa MM, Nieminen H, Alho P and KellokumpuLehtinen P: Biomarker evidence of DNA oxidation in lung cancer patients: association of urinary 8-hydroxy-2'-deoxyguanosine excretion with radiotherapy, chemotherapy, and response to treatment. FEBS Lett 409: 287-291, 1997. 
24. Miyake H, Hara I, Gleave ME and Eto H: Protection of androgen-dependent human prostate cancer cells from oxidative stress-induced DNA damage by overexpression of clusterinand its modulation by androgen. Prostate 61: 318-323, 2004.

25. Barash H, Gross E, Edrei Y, Israel A, Cohen I, Corchia N, Ben-Moshe T, Pappo O, Pikarsky E, Goldenberg D, Shiloh Y, Galun E and Abramovitch R: Accelerated carcinogenesis following liver regeneration is associated with chronic inflammation-induced double-strand DNA breaks. Proc Natl Acad Sci USA 107: 2207-2212, 2010.

26. Fujita N, Horiike S, Sugimoto R, Tanaka H, Iwasa M Kobayashi Y, Hasegawa K, Ma N, Kawanishi S, Adachi Y and Kaito M: Hepatic oxidative DNA damage correlates with iron overload in chronic hepatitis C patients. Free Radic Biol Med 42: $353-362,2007$
27. Poli G and Parola M: Oxidative damage and fibrogenesis. Free Radic Biol Med 22: 287-305, 1997.

28. Sumida Y, Nagashima M, Yoh T, Nakajima Y, Ishikawa H, Mitsuyoshi H, Sakamoto Y, Okanoue T, Kashima K, Nakamura H and Yodoi J: Serum thioredoxin levels as an indicator of oxidative stress in patients with hepatitis. J Hepatol 33: 616-622, 2000.

29. Collins A, Cadet J, Epe B and Gedik C: Problems in the measurement of 8-oxoguanine in human DNA. Report of a workshop, DNA oxidation, held in Aberdeen, UK, 19-21 January 1997. Carcinogenesis 18: 1833-1836, 1997. 